\title{
Meningkatkan Kualitas dan Vitalitas Kawasan Melalui Fasilitas Geopark Lumpur Sidoarjo sebagai Katalisator
}

\author{
Widya Wahyuning Permata dan Defry Agatha Ardianta \\ Departemen Arsitektur, Fakultas Arsitektur Desain dan Perencanaan, Institut Teknologi Sepuluh Nopember (ITS) \\ e-mail: agathadefry@arch.its.ac.id
}

\begin{abstract}
Abstrak-Fenomena semburan lumpur Sidoarjo adalah peristiwa meletusnya gunungan lumpur di Kecamatan Porong, Sidoarjo di Jawa Timur, Indonesia yang menyebabkan kawasan tersebut mengalami berbagai dampak negatif sehingga menjadi area yang ditinggalkan oleh masyarakat. Geopark sebagai objek rancang yang berada di kawasan lindung geologi menjadi sebuah respon arsitektur untuk menghidupkan area tersebut dengan menggunakan pendekatan katalis untuk mendorong dan mengarahkan pada perkembangan berikutnya. Objek rancang mengeksplorasi pengalaman spasial untuk menciptakan persepsi baru terhadap kawasan terdampak lumpur yang bertujuan menjadi katalisator kawasan yang berkembang menjadi lebih baik, serta menyampaikan makna yang dimiliki wilayah terdampak kepada masyarakat.
\end{abstract}

Kata Kunci-Lumpur Sidoarjo, Geopark, Katalis.

\section{PENDAHULUAN}

L UMPUR Sidoarjo adalah peristiwa menyemburnya Jlumpur panas di lokasi pengeboran Lapindo Brantas Inc. di Dusun Balongnongo Desa Renokenongo, Kecamatan Porong, Kabupaten Sidoarjo, Jawa Timur, Indonesia, sejak tanggal 29 Mei 2006 (Gambar 1). Semburan lumpur panas ini menyebabkan tergenangnya kawasan permukiman, pertanian, dan perindustrian, serta mempengaruhi aktivitas perekonomian masyarakat. kawasan tersebut berubah menjadi 'Kota Mati' karena hilangnya fungsi kehidupan (Gambar 2).

Terdapat perbedaan level habitable yang berbeda tiap daerah yang ditunjukkan dalam 3 aspek yaitu ketinggian, iklim, dan sumber air [1]. Pada konteks objek rancang dapat dikategorikan dalam area yang uninhabitable karena berbagai faktor seperti kondisi fisik infrastruktur yang rusak, kondisi lingkungan yang tercemar seperti tanaman dan juga perairan serta udara sekitar yang tidak baik untuk kesehatan manusia yang tinggal dalam waktu jangka panjang dan kondisi sosial yang berubah (Gambar 3).

Oleh karena itu, kawasan tersebut ditinggalkan oleh manusia didalamnya karena bencana yang menimpa. Ketika ditinggalkan, maka ia akan kehilangan fungsi kehidupan dan tempat tersebut menjadi "places in the memory". Kawasan tersebut menjadi tidak berfungsi seperti semula. Nilai kawasan yang awalnya merupakan area yang vital yaitu perdagangan dan pertanian berubah.

Skenario revitalisasi yang memungkinan untuk menghidupkan area yang ditinggalkan menurut Giorgio

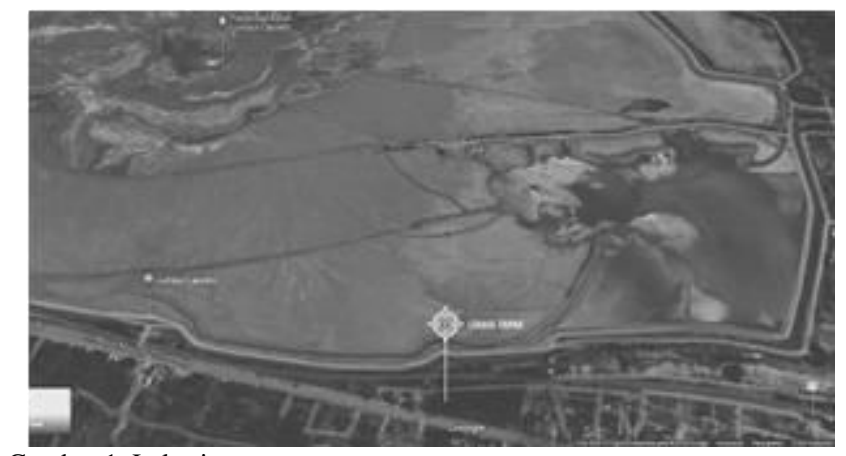

Gambar 1. Lokasi.

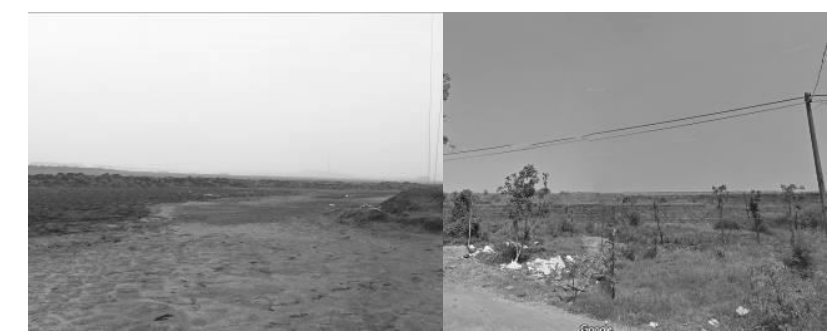

Gambar 2. Kondisi lokasi.

Verdiani, Per Cornell (Architecture, Archaelogy and Contemporary City Planning) dibagi menjadi dua tipe yaitu pemulihan untuk pariwisata dan aktivitas manusia yang baru. Tempat atau wilayah yang ditinggalkan adalah tempat yang menarik untuk arsitektur, dibangun sesuai tradisi lama sehingga menjadi kebangkitan dari masa lalu. Dengan memberikan atribut arti baru pada wilayah yang ditinggalkan, wilayah tersebut bisa mendapatkan fungsi baru didalamnya [2].

Menurut RT RW Kabupaten Sidoarjo 2009-2029 dan PP No 26 Tahun 2008, lokasi terdampak lumpur merupakan Kawasan Lindung Geologi sehingga perkembangan dalam kawasan ini berarti hanya dapat dikembangkan secara terbatas. Program yang ditawarkan adalah fasilitas geopark atau disebut taman geologi. Menurut UNESCO, geopark adalah sebuah daerah dengan panjang yang sudah ditetapkan dengan jelas dan memiliki panjang permukaan yang cukup luas untuk pembangunan ekonomi lokal. Geopark memiliki konsep dasar edukasi, konservasi, dan pembangunan berkelanjutan (Gambar 4). Jika dikaitkan dengan skenario revitalisasi menurut Giorgio Verdiani dan Per Cornell, program geopark dapat mewadahi bentuk pariwisata maupun aktivitas manusia yang baru. 


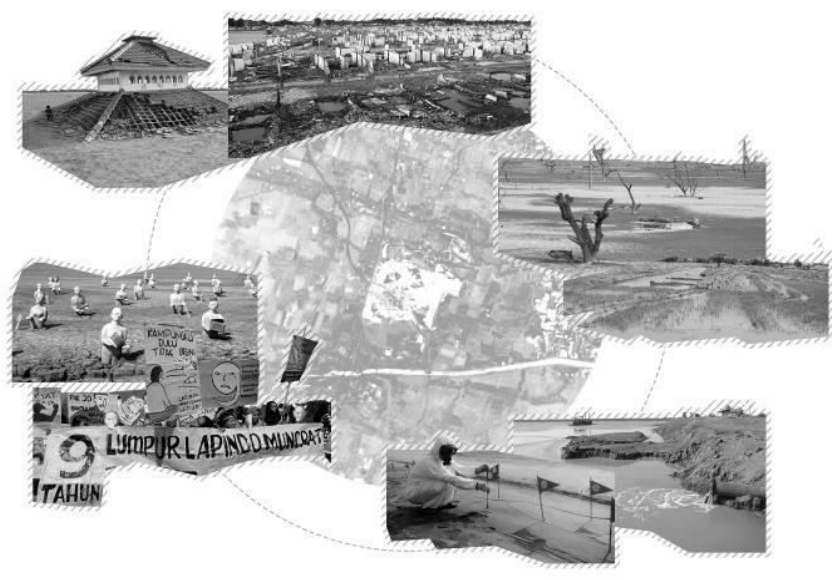

Gambar 3. Dampak bencana semburan lumpur.

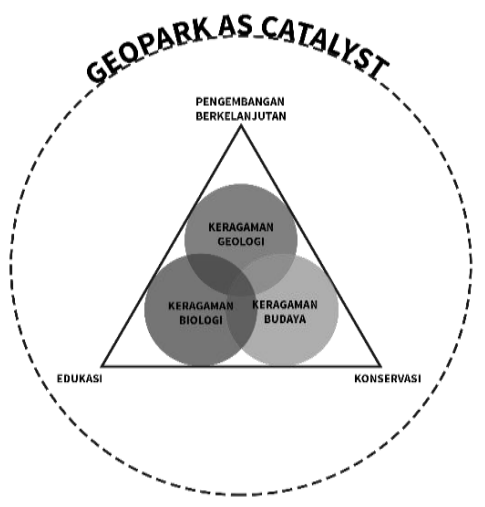

Gambar 4. Konsep pengembangan geopark.

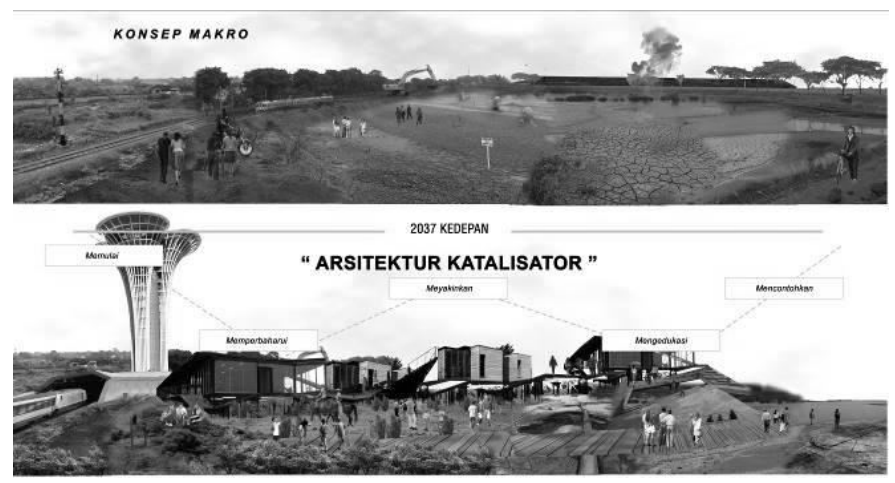

Gambar 5. Konsep utama objek desain.

Dengan adanya program fasilitas geopark diharapkan dapat merangsang perubahan kualitas dan vitalitas ruang dengan memanfaatkan kembali potensi lahan terdampak lumpur. Persepsi negatif masyarakat terhadap wilayah terdampak lumpur dapat dirubah menjadi sesuatu yang positif karena dari bencana tersebut masyarakat dapat belajar dari dampak negatif maupun pemanfaatannya. Objek desain harus menimbulkan semangat baru dan membuat masyarakat bangkit dari kesedihan akan bencana yang telah terjadi.

\section{II.METODA PERANCANGAN}

Di dalam merancang proses merancang suatu objek terdapat berbagai macam cara untuk memulai proses merancang, salah satu cara yang di gunakan adalah menggunakan metode

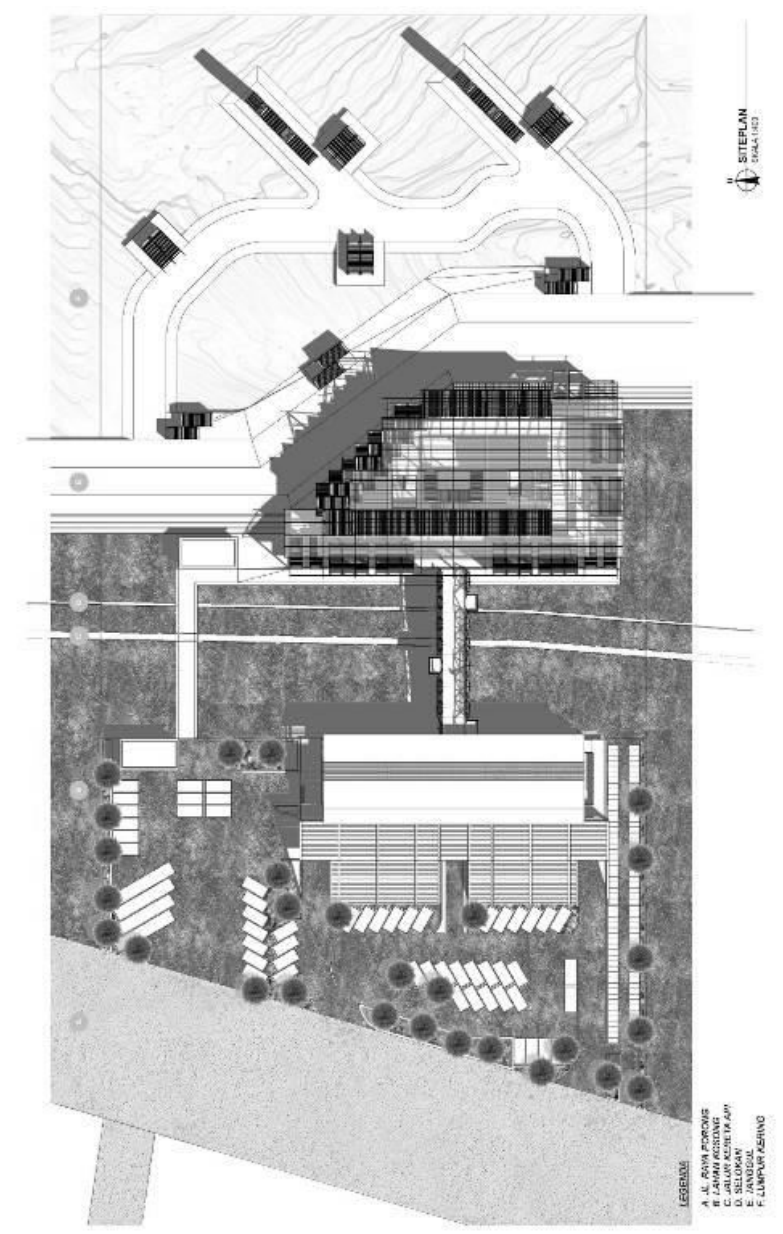

Gambar6. Siteplan geopark.

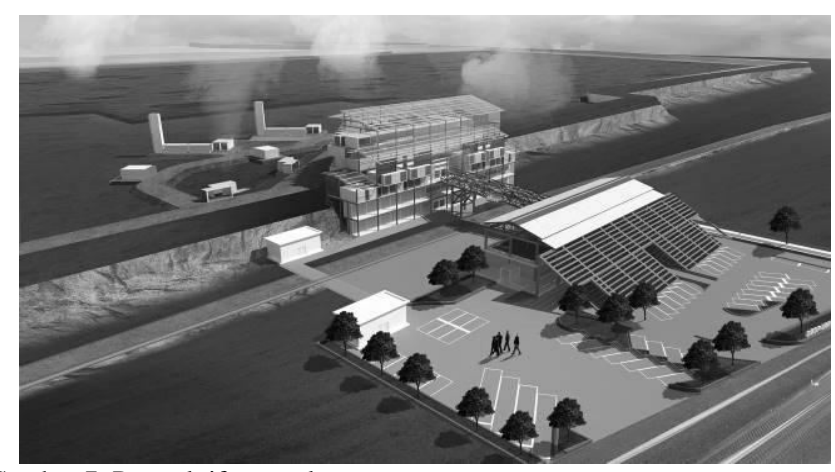

Gambar 7. Perspektif geopark.

Context Analysis yang merupakan metode untuk membantu memahami berbagai informasi, membangun hubungan antara pengembangan perancangan dan konteks, serta berkontribusi dalam peningkatan kualitas lingkungan bangunan [3]. 4 langkah sebagai berikut.

1. Menemukan site dan menghitung luas fisik berdasarkan kebutuhan

2. Menganalisa kualitas dari site

3. Memutuskan respon rancangan

4. Menjelaskan dan mengilustrasikan respon rancangan Metode tersebut digunakan karena objek desain memiliki keterkaitan yang sangat erat dengan kondisi konteks. Setelah memahami konteks, diterapkan pendekatan katalis dalam mengolah konsep. 


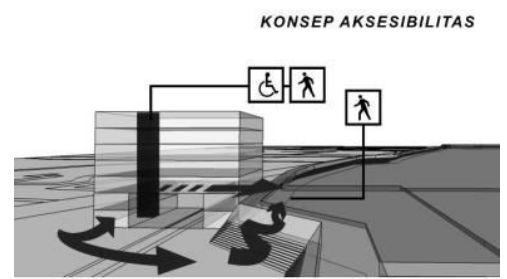

Gambar 8. Transformasi massa.

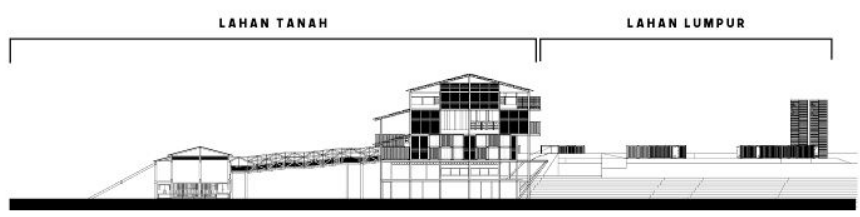

Gambar 9. Area penggunaan lahan tanah dan lumpur.

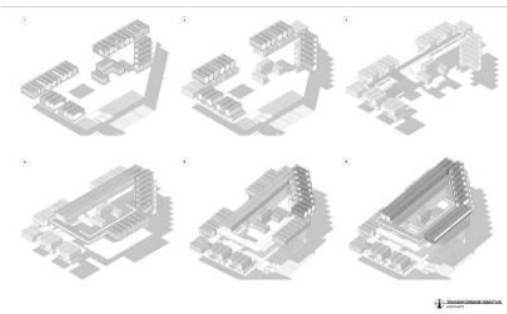

Gambar 10. Transformasi tatanan peti kemas.

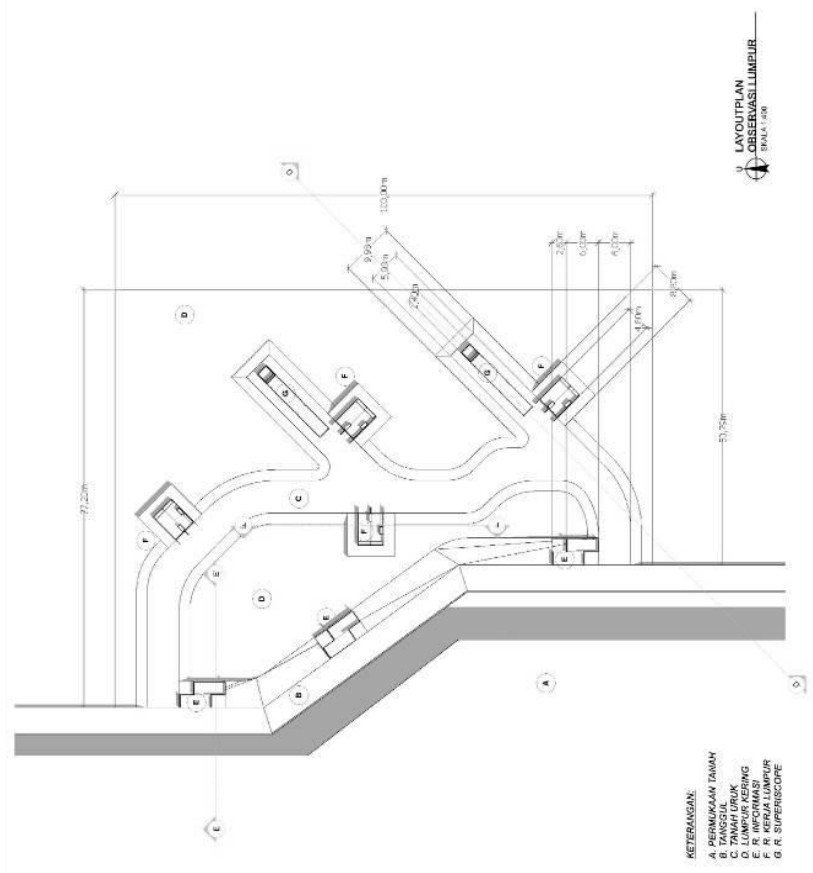

Gambar 11. Layoutplan observasi lahan lumpur.

Dalam ranah penataan kota/kawasan, pemberian katalis digunakan untuk mendorong perkembangan suatu kota/kawasan yang disebut dengan Urban Catalyst. Katalis merupakan sebuah fasilitas (bangunan) yang menghasilkan pembangunan perkotaan di lingkungan sekitar. Katalis adalah elemen kota yang terbentuk oleh kotanya dan pada gilirannya membentuk konteksnya [4]. Katalis pada objek rancang memodifikasi konteks namun tidak merusak konteks melainkan men-trigger masyarakat untuk berhubungan dengan konteks secara lebih positif. Objek desain juga berada didekat fungsi komersial yaitu pusat Krembung yang merupakan kawasan industri, pertanian dan perdagangan

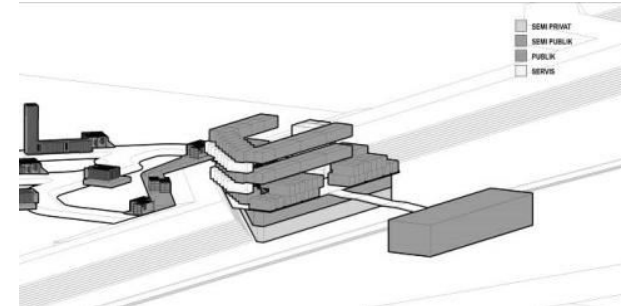

Gambar 12. Konsep zonasi.

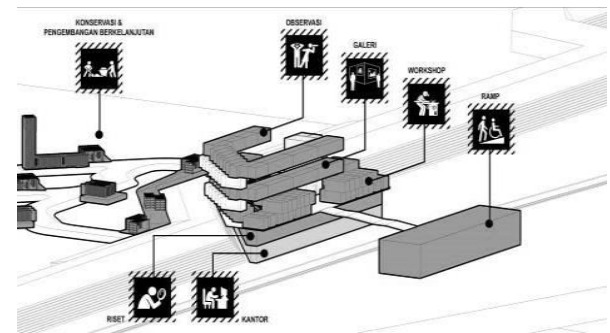

Gambar 13. Program.

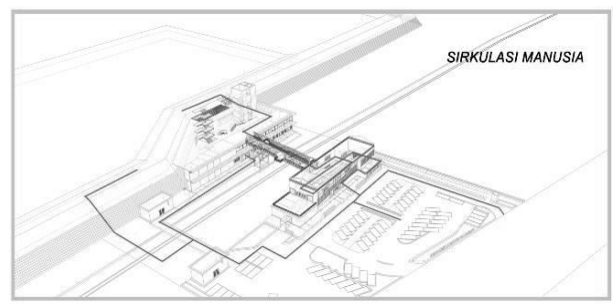

Gambar 14. Konsep aksesibilitas.

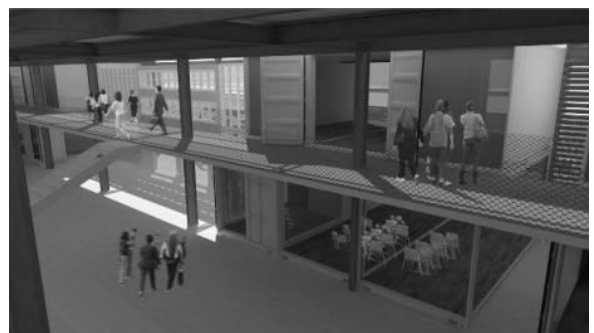

Gambar 15. Area workshop.

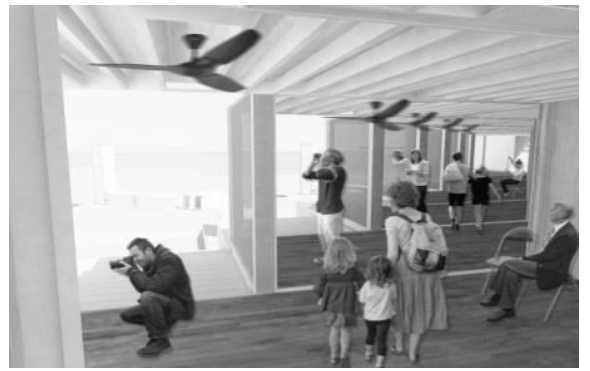

Gambar 16. Area observasi indoor.

sehingga memiliki peluang besar untuk menarik massa dan menjadi trigger yang baik untuk konteks dan kawasan sekitarnya.

\section{EKSPLORASI DAN HASIL}

Konsep utama yang ditawarkan untuk merangsang perubahan adalah objek arsitektur sebagai media katalisator kawasan yang saat ini merupakan area un-inhabitable dan minimnya fungsi kehidupan dengan menjadi generator awal dalam memulai kondisi habitable (Gambar 5). Habitable disini 


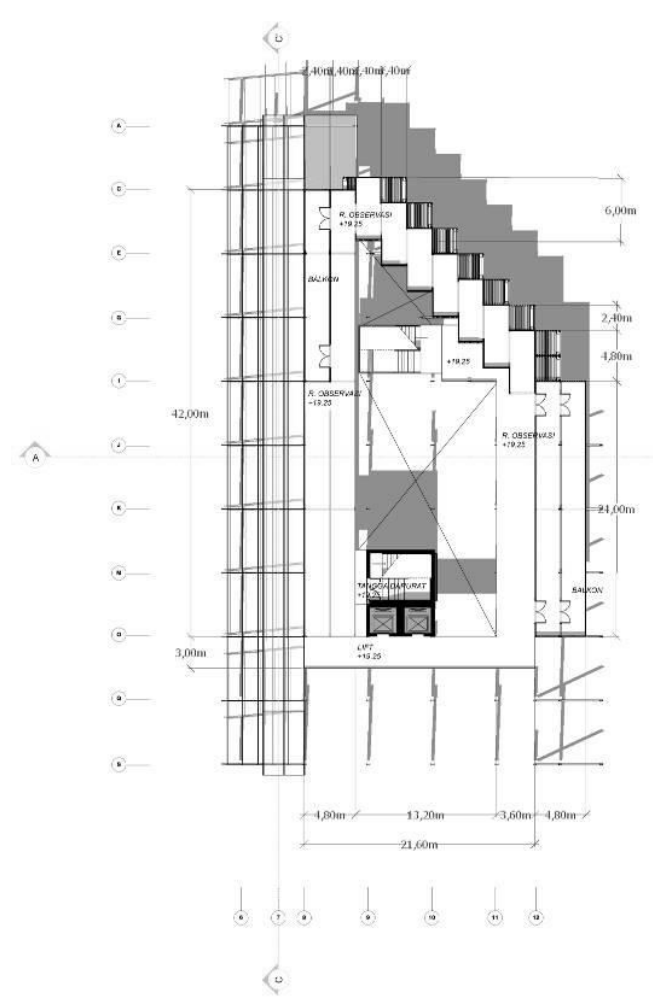

Gambar 17. Denah lantai 6: Area observasi indoor.

bukan menciptakan secara langsung sebuah area yang siap dihuni/ditinggali oleh masyarakat melainkan menjadi awalan yang memfasilitasi masyarakat untuk beraktifitas dalam memanfaatkan dan memperbaiki lahan yang tercemar. Masyarakat ditarik untuk datang dengan tujuan meyakinkan masyarakat jika area terdampak lumpur tersebut dapat berguna bagi kehidupan masyarakat kedepannya dengan diberi wadah edukasi dan pengembangan lumpur. Objek arsitektur tidak akan berhasil jika manusianya tidak mendukung karena objek tersebut hanyalah media yang menjadi perantara antara manusia dan konteksnya untuk mempercepat proses atau perubahan yang dituju yaitu perkembangan kualitas dan vitalitas ruang yang lebih baik.

Sebagai arsitektur katalis, terdapat 4 konsep yang ditawarkan untuk mencapai katalis itu sendiri yaitu mendefinisikan ulang arti kawasan, menghubungkan masyarakat sekitar, menggunakan sistem ramah lingkungan dan interaktif.

Untuk merubah persepsi negatif terhadap lumpur, maka perlu menciptakan definisi baru area terdampak lumpur dengan arti yang berbeda untuk tujuan yang lebih baik (Gambar 6). Usaha yang dilakukan adalah dengan memanfaatkan hamparan lumpur sebagai sumber daya masyarakat untuk meningkatkan nilai perekonomian melalui pengolahan lumpur pada program workshop atau riset. Selain itu memanfaatkan hamparan lumpur menjadi area observasi langsung dengan memberikan beberapa program didalamnya seperti area informasi, tempat bekerja mengolah lumpur dan observasi. (Gambar 7)

Kemudian untuk menghidupkan kawasan, maka dibutuhkan kehadiran manusia didalamnya. Objek desain harus dapat

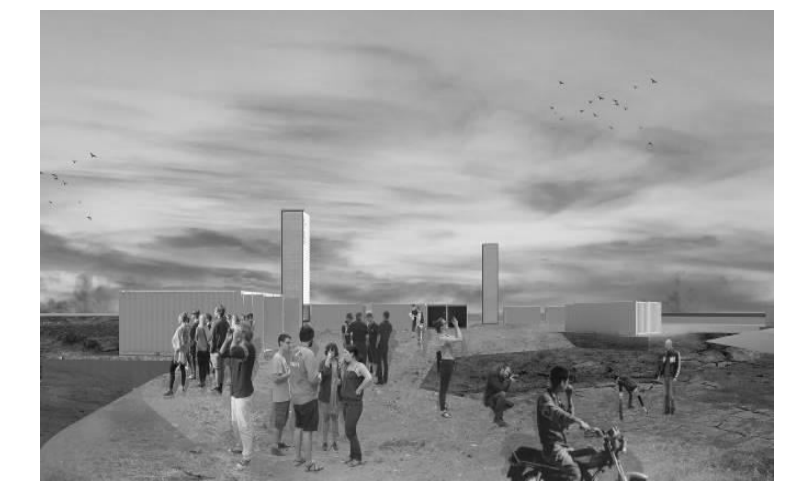

Gambar 18. Lahan lumpur.

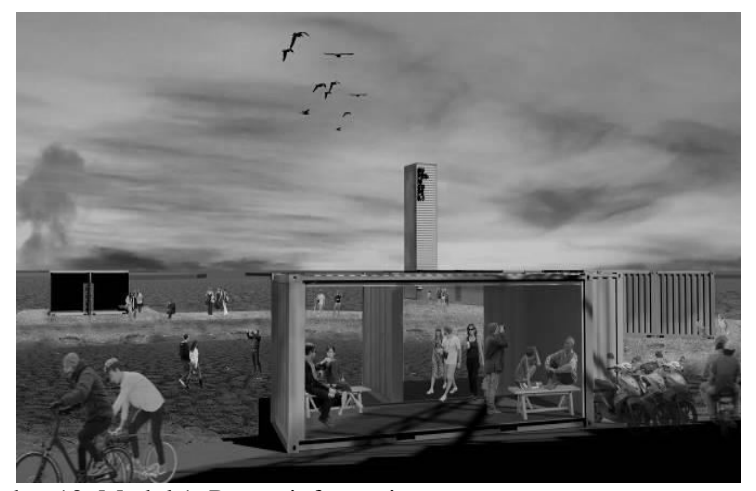

Gambar 19. Modul 1: Ruang informasi.

mewadahi berbagai kalangan masyarakat dari segi umur, pekerjaan, dll yang berada disekitar kawasan area terdampak maupun masyarakat luar. Karena saat ini akses untuk menuju lumpur sulit, maka askesibilitas menjadi sangat penting pada objek desain untuk memudahkan masyarakat menuju lahan lumpur Sidoarjo (Gambar 8).

Objek desain menggunakan sistem ramah lingkungan berarti terintegrasi dengan konteks lokasi dan tidak merusak konteksnya sesuai dengan konsep katalis sendiri. Hal tersebut diterapkan pada konsep tatanan massa, struktur dan material.

Sedangkan interaktif memiliki arti saling berhubungan dan mempengaruhi. Karena tujuan dari objek desain adalah untuk merangsang perubahan dari dampak negatif lumpur, maka dilakukan beberapa upaya agar dapat menimbulkan pengaruh pada peletakan program dan desain ruang.

1. Konsep Bentuk dan Tatanan Massa

Bentuk bangunan diambil dari bentuk tapak yaitu trapesium dan persegi panjang yang dibagi dengan grid 6x6 karena menyesuaikan ukuran peti kemas yang digunakan pada bagian atas bangunan dan lahan lumpur.

Objek desain terdiri dari 2 area yaitu lahan asli dan lahan lumpur (Gambar 9). Pada lahan asli terdiri dari 2 massa terpisah berbentuk persegi panjang dan trapesium dengan susunan peti kemas diatasnya (Gambar 10). Sedangkan pada lahan lumpur terdiri dari beberapa modul peti kemas yang disusun menyebar di beberapa titik agar pengguna dapat merasakan pengalaman langsung terhadap lumpur lebih luas (Gambar 11).

Peti kemas digunakan karena tepat untuk kondisi tanah yang kurang baik. Peti kemas memiliki permukaan yang luas tanpa membutuhkan struktur penopang khusus. Peti kemas yang 


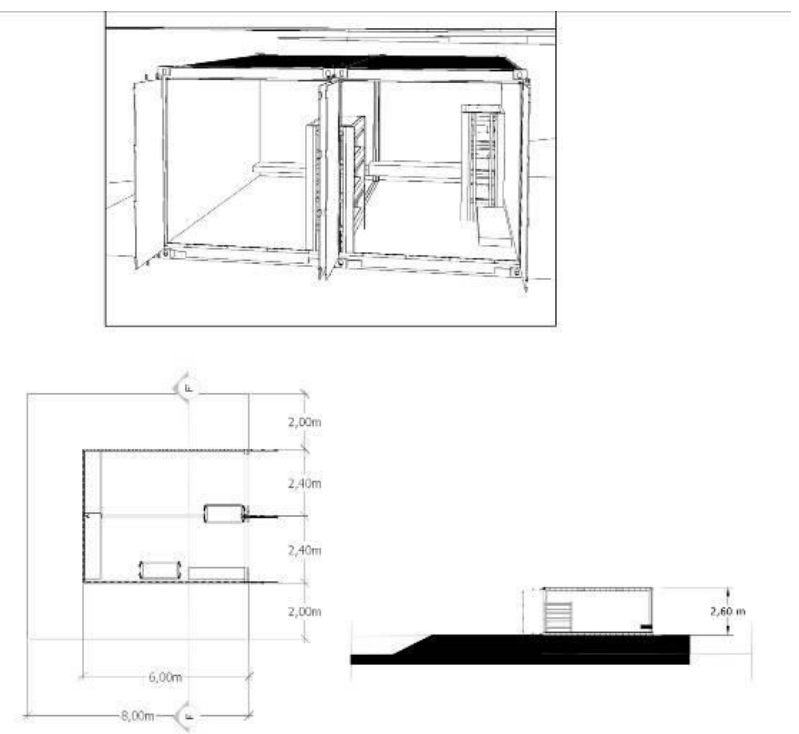

Gambar 20. Modul 2: Ruang kerja lumpur.

digunakan pada bangunan terdapat 2 jenis yaitu ukuran 20 kaki dan 40 kaki. 20 kaki memiliki panjang $6 \mathrm{~m}$ dan lebar 2,4 m, sedangkan 40 kaki memiliki panjang $12 \mathrm{~m}$ dan lebar 2,4 m.

Massa dibentuk dengan elevasi yang berbeda yang semakin meninggi menuju tanggul dan dihubungkan oleh jembatan. Jembatan berada diatas rel kereta api agar pengguna dapat melewati area tersebut dengan lebih aman. Dengan massa yang memiliki ketinggian lebih dari tanggul, maka berbagai kalangan akan lebih mudah melihat semburan dan hamparan lumpur sebagai edukasi dan pengalaman dengan lebih aman seperti untuk pengguna dibawah umur dan pengguna disabilitas.

\section{Konsep Zoning}

Zoning pada bangunan dibedakan menjadi 4 (Gambar 12 dan 13), yaitu: Publik terdiri dari ramp, workshop, galeri, observasi, konservasi dan pengembangan berkelanjutan. Area public adalah area yang bebas dimasuki oleh seluruh pengguna. Semi publik terdiri dari area riset dimana pengguna hanya dapat memasuki ruang dengan ketentuan khusus. Semi privat terdiri dari area kantor dimana pengguna dapat memasuki ruang dengan ketentuan khusus namun area lebih privasi digunakan untuk para pekerja. Sedangkan area servis terdiri dari area servis, tangga darurat, lift dan jembatan.

\section{Konsep Sirkulasi}

Sirkulasi pengguna pada objek desain dapat melalui 2 jalur yaitu melalui bangunan dan tangga tanggul untuk menuju lahan lumpur (Gambar 14). Jika melalui bangunan, pengguna akan mengitari ramp pada bangunan pertama terlebih kemudian melewati jembatan untuk menuju bangunan kedua karena dipisahkan oleh rel kereta api diantaranya. Desain ini merupakan konsep dari integrasi antara objek desain dan konteks agar tidak merusaknya. Di bangunan kedua, pengguna akan menaiki sedikit tangga yang langsung berhubungan dengan tanggul. Sedangkan untuk pengguna disabilitas dapat menikmati kawasan lumpur dari dalam bangunan kedua saja karena kondisi lahan berlumpur tidak memungkinkan untuk
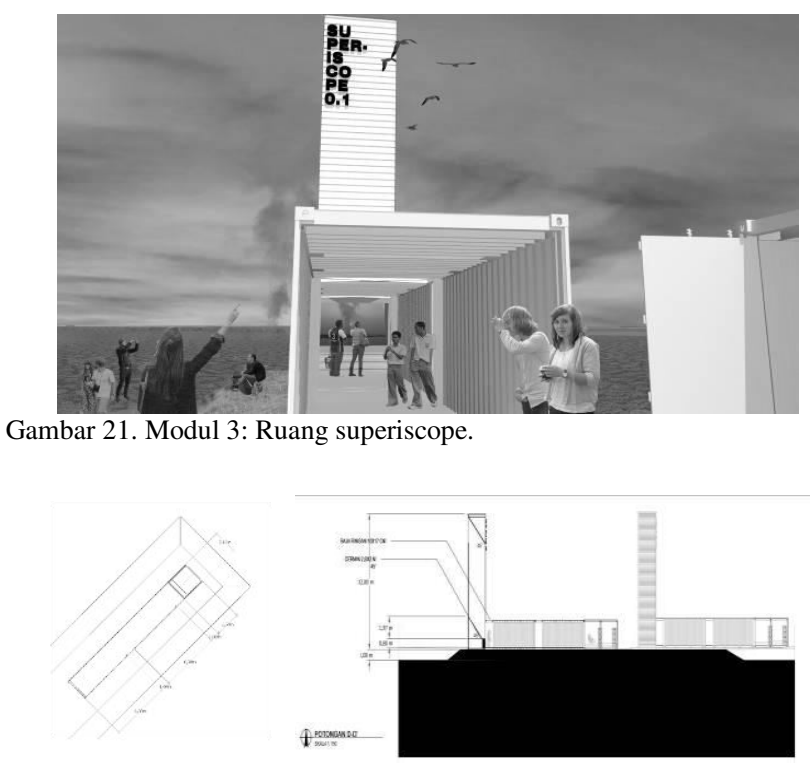

Gambar 22. Modul 3: Denah dan potongan ruang kerja lumpur.

dilewati. Pada bangunan kedua terdapat lift dan tangga sebagai akses menuju lantai ke lantai.

Sedangkan sirkulasi diatas lahan lumpur dibentuk dengan pola mengelilingi lumpur kering dibentuk dari garis-garis vertikal yang berasal sejajar dengan garis jalan raya, garis diagonal yang mengarah ke pusat semburan dan garis horizontal yang tegak lurus dengan arah garis dari jalan raya. Dari garis-garis tersebut dibentuk sirkulasi dengan jarak 6meter yang dapat dilalui oleh pergerakan manusia maupun kendaraan seperti sepeda atau motor yang biasa digunakan oleh masyarakat untuk mengelilingi tanggul. Bagian ujung disengaja mengarah ke pusat semburan dengan tujuan menunjukkan semburan lumpur dari jarak jauh. Pengguna objek juga dapat turun ke lumpur kering untuk mendapatkan pengalaman langsung. (Gambar 11)

\section{Hasil Desain dan Aktivitas}

Aktivitas utama pada objek desain adalah mempelajari dan mengamati secara langsung lumpur untuk merangsang perubahan kualitas dan vitalitas ruang melalui 2 area yaitu indoor dan outdoor. Area indoor adalah ruang riset, workshop, galeri dan observasi. Sedangkan area outdoor adalah tiga modul peti kemas yang berada pada lahan lumpur.

a. Workshop

Area riset dan workshop berfungsi sebagai tempat edukasi dan produksi material dari pengolahan lumpur untuk membantu meningkatkan perekonomian masyarakat (Gambar 15). Area workshop didesain dengan 2 level yang berbeda dengan susunan peti kemas. Level 1 adalah area pamer produk dan ruang workshop terbuka sehingga pengguna yang menuju lahan lumpur akan selalu mendapatkan informasi tetang produk hasil pengolahan dari kegiatan workshop yang bermanfaat. Sednagkan level 2 adalah ruang workshop semi tertutup.

\section{b. Galeri}

Area galeri adalah tempat edukasi tentang pra-bencana, saat bencana dan pasca-bencana. Masyarakat akan teredukasi melalui pameran yang disajikan sesuai alur yang diberikan. 


\section{c. Observasi}

Area observasi adalah ruang untuk mengamati lahan terdampak lumpur dan sekitarnya dari level ketinggian bangunan tertinggi (Gambar 16). Area terbagi menjadi 3 yaitu bagian utara, timur, dan barat yang memiliki pemandangan yang berbeda. Pemandangan terbaik adalah area utara dan barat karena berhdapan dengan hamparan lumpur (Gambar 17).

Di lahan lumpur, pengguna dapat merasakan pengalaman secara langsung berada pada area lumpur melalui urukan tanah yang berada pada lumpur kering maupun berdiri diatas lumpur kering secara langsung (Gambar 18). Pada area tersebut terdapat 3 program ruang yang didesain menggunakan peti kemas. Peti kemas diletakkan di tanah uruk pada lumpur kering untuk mewadahi aktivitas.

Program pertama adalah ruang informasi yang berguna sebagai pusat informasi jika ingin mengetahui suatu informasi dari para pekerja di lahan lumpur. Tempat ini juga merupakan titik para ojek keliling beristirahat dan menunggu pendatang yang ingin mengelilingi tanggul untuk mengetahui area lumpur (Gambar 19).

Program kedua adalah ruang kerja lumpur yang berguna sebagai tempat mengolah lumpur jika ingin mengambil sampel dan kebutuhan lainnya (Gambar 20). Aktivitas pengguna pada lahan lumpur biasanya adalah mengambil sampel lumpur, air semburan lumpur ataupun material-material yang ada pada lumpur seperti batuan. Dengan adanya fasilitas tersebut, maka dapat mempermudah pengguna dalam mencari peralatan, menyimpan atau pun mengolah sebagian lumpur dalam dua buah peti kemas yang disambung.

Dan program ketiga adalah ruang superiscope yang berguna sebagai tempat mengamati area lumpur dari periskop raksasa yang mengarah langsung pada pusat semburan lumpur (Gambar 21). Sistem ruang ini seperti periskop yang menggunakan cermin namun didesain dalam bentuk lebih besar yaitu skala manusia menggunakan peti kemas. Peti kemas diputar vertikal 90' untuk mendapatkan ketinggian yang sesuai dan disambung dengan peti kemas horizontal untuk menahan gaya horizontal peti kemas vertikal agar tidak jatuh (Gambar 22).

Fasilitas-fasilitas tersebut membantu untuk men-trigger pengguna berhubungan dengan lumpur secara langsung maupun tidak langsung dan memanfaatkannya untuk menciptakan perubahan yang lebih baik dimana sebelumnya memiliki kesan negatif. Aktivitas edukasi dan pengolahan lumpur menjadi suatu produk merupakan cara untuk menciptakan kehidupan baru di kawasan tersebut dan dapat meningkatkan perekonomian masyarakat sehingga sumber daya yang berlimpah tidak disia-siakan namun untuk terus dipelajari dan dikembangkan.

\section{KESIMPULAN}

Tujuan utama dari objek desain adalah untuk merangsang perubahan kualitas dan vitalitas ruang dengan memanfaatkan kembali potensi lahan terdampak lumpur. Dengan menggunakan pendekatan katalis, maka dapat membantu objek desain menjadi langkah awal pada kawasan yang mampu mendorong pada perkembangan selanjutnya dan meningkatkan nilai dari sumber daya lumpur serta pereknomian masyarakat sekitar.

\section{DAFTAR PUSTAKA}

[1] C. A. Doxiadis, Action for Human Settlements. Athens: Athens Publishing Center, 1975.

[2] G. Verdiani and P. Cornell, "Architecture, Archaeology, and Contemporary City Planning," 2014.

[3] The Strategic Planning Unit Mornington Peninsula Shire Council, "The 4 Step Guide to Context Analysis and Design Response," 2015.

[4] W. Attoe and D. Logan, American Urban Architecture: Catalysts in The Design of Cities. Berkeley: University of California Press, 1989. 